\title{
Specific Features of Thermal Systems of Induration Machines for Pellet Production from Iron-ore Concentrates of Different Types
}

\section{V. Braginn, A. A. Solodukhin ${ }^{1}$, A. V. Starodumov ${ }^{1}$, Yu. G. Yaroshenko², Celso de Jesus Silva ${ }^{3}$, and Gunter Costa Oliveire Hahn ${ }^{3}$}

${ }^{1}$ TOREX R\&D Company, 620041, P.O. Box No.169, Osnovinskaya 8, Ekaterinburg, Russia

${ }^{2}$ Ural Federal University, 620002, Mira 19, Ekaterinburg, Russia

${ }^{3}$ Vale S.A., Pelletizing Department, Av.Dante Michellini, 550029090900 Vitoria ES Brazil

\section{Abstract}

Pellets are one of the main types of iron-ore raw materials used in ferrous metallurgy.

Corresponding Author:

V. V. Bragin

v.bragin@torex-npvp.ru

Received: 6 June 2018

Accepted: 15 June 2018

Published: 17 July 2018

Publishing services provided by Knowledge $\mathrm{E}$

(c) V. V. Bragin et al. This article is distributed under the terms of the Creative Commons

Attribution License, which permits unrestricted use and redistribution provided that the original author and source are credited.

Selection and Peer-review under the responsibility of the TIM'2018 Conference Committee.
In Russia, the overall production of this iron-ore raw material is continuously growing. The analysis of pelletizing technologies over the last years has shown changes in requirements for product quality, process performance, heat and power parameters, environmental performance and production conditions of both fired and pre-reduced pellets. The article provides the analysis of technological and structural defects of conveyor-type induration machines. In order to remove these defects, we have developed an integrated technology for the production of fired pellets of various purposes. This technology made it possible to create an energy-efficient thermal system of the induration machine that has no counterparts in the world. This thermal system takes into account characteristics of the initial raw material. Its implementation at Mikhailovsky GOK in Russia provided a specific natural gas consumption within 8-9 $\mathrm{nm}^{3} / \mathrm{t}$ of pellets and specific energy consumption less than $36 \mathrm{~kW} \cdot \mathrm{h} / \mathrm{t}$ of pellets. These parameters were received by mathematical modelling and introduction of two-layer drying in the pellet induration process. The new induration technology has been implemented in Brazil and is now spreading at other plants in Russia.

Keywords: pellets, iron-ore concentrates, induration machines, thermal systems, two-layer charging, pellet drying

\section{Introduction}

Steel is the most widespread constructional material and over $90 \%$ of steel is made as per 'blast furnace - oxygen converter' and 'DRI/HBI production in shaft furnaces electric arc furnace' process routes [1]. Therefore, improved efficiency of agglomerated iron-ore raw material production is an important problem and cost efficiency of the 
metallurgical industry as a whole depends on solution of this problem [2]. In Russia, the overall production of agglomerated iron-ore raw materials exceeds $100 \mathrm{Mtpa}$, of which the production of iron-ore pellets is over $40 \mathrm{Mtpa}$ [3]. In addition, over the period from 2015 to 2018 the overall production of iron-ore pellets in Russia increased by more than 10 Mpta due to start-up of Induration Machine No.3 at Mikhailovsky GOK (Zheleznogorsk) and Induration Machine No.3 at Stoilensky GOK (Stary Oskol) $[4,5]$. Moreover, plans for higher pellet consumption have been announced [6].

\section{Content}

For the last 10 years the requirements for product quality, process performance, heat and power parameters, environmental performance and conditions for production of metallurgical raw materials have changed drastically. Firstly, due to a sharp rise in prices for energy resources, enhancement of energy efficiency has become one of the high-priority tasks of any producer. Secondly, product quality standards increased significantly, which is determined by a slowdown in growth rates of iron-ore raw material consumption and transition of the industry from extensive development (production ramp-up, expansion into new markets) to intensive development (cost reduction, pellet quality improvement). Thirdly, for the last 10 years DRI production has grown by more than $60 \%$, thus providing an increase in demand for high-quality pellets used for further metallization. Fourthly, market saturation and competition have made pellet producers expand the circle of their customers and range of their products, which requires a flexible system of production rearrangement. All these determined the search for new approaches to arrangement of gas and air flows and thermal systems in conveyor-type induration machines, the analysis of which is the purpose of this article.

The conveyor-type induration machines used in Russia and abroad (hereinafter referred to as (IM) have a number of technological and structural drawbacks that do not allow producing high-quality pellets of various purposes with necessary efficiency. The increase in costs during production is determined by:

1. of the conveyor-type induration machine as well as properties of green pellets depending on concentrate quality, burden composition and preparation;

2. large consumptions of electric energy and gas;

3. low quality of produced pellets; and

4. significant quantity of dust and gas emissions into the environment. 
The main drawbacks of CIM designs used in Russia and abroad are:

1. low efficiency in drying the layer of green pellets, imperfect design of separate sections and drying zone as a whole;

2. inadequate use of heat of CIM's gas and air flows, including high-temperature (overflow) air;

3. unbalanced relationship between the areas of the process zones regarding recirculation flows of the heat medium;

4. large quantity of burners; and

5. significant volume of hot gases discharged into the atmosphere.

In order to satisfy the modern requirements for productivity, product quality, heat and energy parameters and environmental safety of production, the existing CIM shall be fully reconstructed or replaced. The integrated technology for production of variouspurpose fired pellets was developed with the use of mathematical modelling and elaborated methodology, including:

1. analysis of possibility to use mineral raw materials of different origin and properties for production of various-purpose pellets;

2. determination of economically feasible conditions for production of adequate concentrates;

3. development of the optimum burden composition considering concentrate quality and requirements for green and fired pellets;

4. calculation of the optimum conditions for heat treatment considering parameters of the initial raw materials and providing the required quantity of the final product; and

5. development of the CIM design providing the required conditions for heat treatment and enabling to produce pellets of required quality with minimum energy consumption and environmental impact.

For creation of the brand new energy-efficient thermal system having no counterparts in the world, the advanced technical developments of TOREX R\&D Company were used. These developments were tested and implemented during modernization of existing iron-ore pelletizing facilities at a number of plants [7-9]. 
Development of the brand new thermal system of the induration machine has required improvement of the mathematical model. The improved mathematical model of the induration machine $[10,11]$ is based on development of new calculation blocks that take into account the specific features of the new CIM design, including several overflow collectors with regard to a new system of multiple gas recirculation, unlike the previous heat-exchange models in the induration machine of old design with one overflow collector.

The improved model made it possible to determine the thermal impact of recycled gases on pellets in individual areas and levels of the treated layer. The model enabled to settle a number of fundamental issues related to minimization of specific fuel consumption and optimization of machine performance due to an increased degree of gas recirculation. Based on mathematical modelling, we determined the optimum process and heat engineering parameters of induration machine operation that provided the basis for development of the induration machine design. The model enabled to obtain the input data for selection of induration machine equipment: exhaust fans, burners, gas cleaning equipment, etc.

The main innovative solutions used for development and creation of the energyefficient thermal system of the induration machine (Figure 1) distinguishing it from the counterparts are [12]:

1. an overflow system, including a central collector and two lateral collectors providing the maximum utilization of the heat of fired pellets from the cooling zone with its selective distribution in a fanless way over the process zones of the induration machine and

2. a gas flue system providing recirculation of the heat medium with a high degree of the utilization of waste heat from the heating, firing and recuperative zones, which provides the minimum quantity of gases discharged into the atmosphere.

Depending on the type of the initial raw material, we developed different options of the new thermal system. In particular, when the pellets are produced from banded iron formations of the Kursk Magnetic Anomaly, with regard to a low specific surface of the concentrate contributing to a high shock temperature, the technical solutions enable to intensify significantly the drying process. For this purpose, the new machine MOK-1$592 \mathrm{M}$ of Mikhailovsky GOK was designed with a three-section drying zone with special exhaust fans transporting gases with a high temperature up to $550^{\circ}$, which made it possible to exclude mixing of gases with different temperatures and intensify drying of the pellet layer without pellet softening and destruction $[13,14]$. 


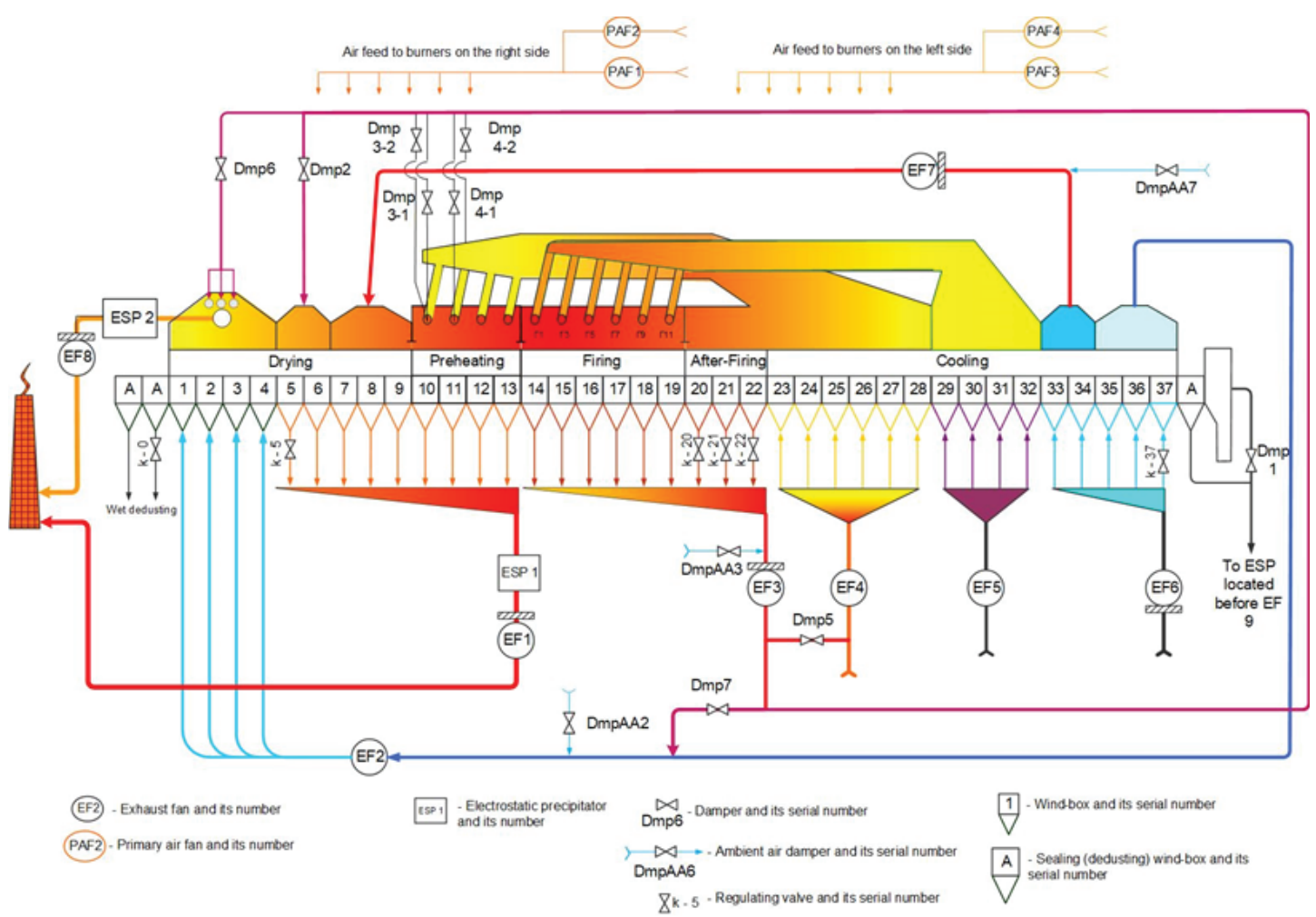

Figure 1: Innovative thermal system of MOK-1-592M.

TABLE 1: Parameters of CIM modernization.

\begin{tabular}{|c|c|c|c|c|}
\hline \multirow[b]{2}{*}{ Parameter } & \multicolumn{4}{|c|}{ Vale, Brazil } \\
\hline & Basic & $\begin{array}{c}\text { After } \\
\text { reconstruction }\end{array}$ & Basic & $\begin{array}{c}\text { After } \\
\text { reconstruction }\end{array}$ \\
\hline Induration machine агеа, m² & \multicolumn{2}{|r|}{278} & \multicolumn{2}{|r|}{430} \\
\hline Productivity, t/h & 306 & 389 & 473 & 619 \\
\hline $\begin{array}{l}\text { Energy consumption for exhaust } \\
\text { fans, } k W \times h / t\end{array}$ & 17.0 & 25.30 & 20.9 & 28.0 \\
\hline Specific fuel consumption, $\mathrm{m}^{3} / \mathrm{t}$ & 14.3 & 10.5 & 14.1 & 10.5 \\
\hline $\begin{array}{l}\text { Specific quantity of gases in the } \\
\text { chimney, } \mathrm{m}^{3} / \mathrm{t}\end{array}$ & 2.7 & 2.0 & 2.4 & 1.9 \\
\hline
\end{tabular}

MOK-1-592M put in operation at Mikhailovsky GOK in April 2016 surpasses the world's best counterparts in energy efficiency and specific consumption of energy resources: specific consumption of natural gas is $8-9 \mathrm{~nm}^{3} / \mathrm{t}$ of pellets, specific consumption of electric energy for production from the pulp to fired pellets is less than 36 $\mathrm{kW} \cdot \mathrm{h} / \mathrm{t}$ of pellets. Moreover, the strength properties of the produced pellets meet the requirements for raw materials used in blast-furnace production and metallization. The range of used concentrates includes a common magnetite concentrate, an upgraded floatation concentrate and, in future, a hematite concentrate. 

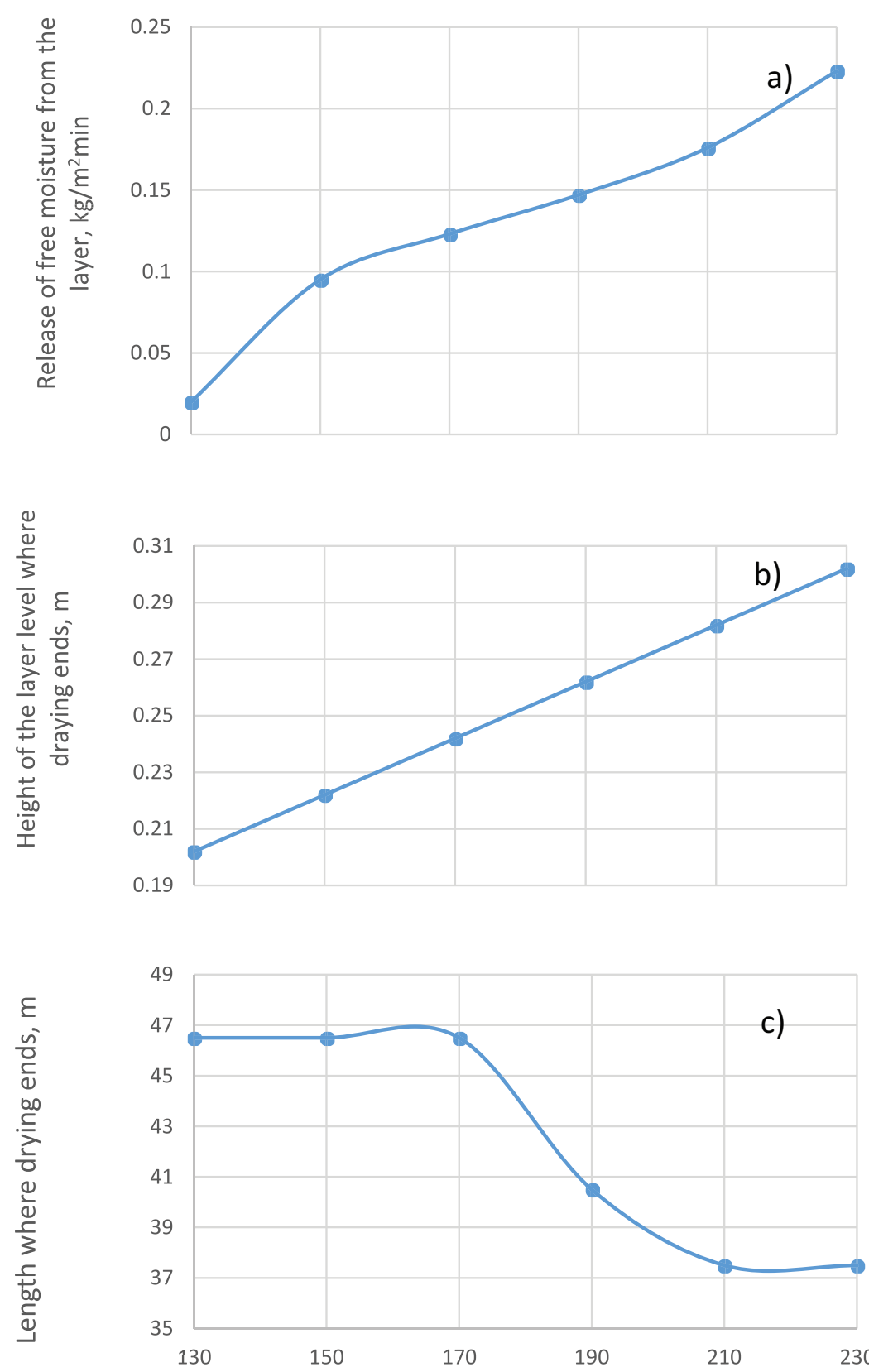

Height of the first (bottom) layer, $\mathrm{mm}$

Figure 2: Calculation results of changing in main process parameters of the drying zones due to the height of the bottom layer during two-layer charging: (a) free moisture release, $\mathrm{kg} / \mathrm{m}^{2} \mathrm{~min}$; (b) layer level where the drying process ends, $\mathrm{m}$; (c) length where drying ends, $\mathrm{m}$.

In Brazil, in particular at Vale's Tubarao Complex, they produce pellets from a thin hematite concentrate with addition of solid fuel. These pellets are characterized by higher density, that is, lower porosity, and require gradual and careful drying. Based on these specific features, for modernization of Induration Machines No.1 and No.2 of 278 


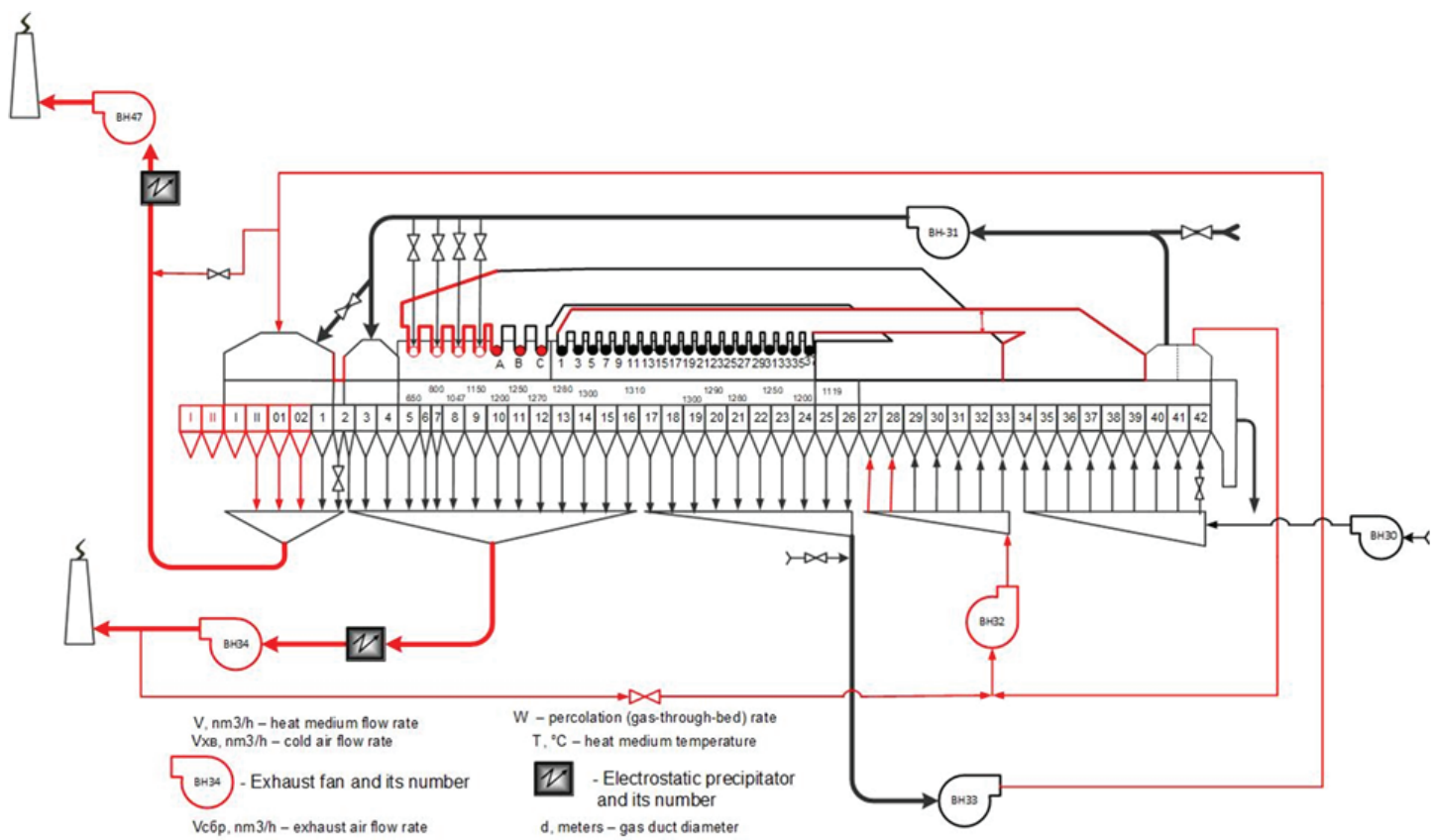

Figure 3: Modernized thermal system of Vale' CIM.

$\mathrm{m}^{2}$ and $430 \mathrm{~m}^{2}$ area, respectively, two-layer charging of green pellets was developed in addition to the new overflow system.

Intensification of operation, especially in the drying zones, is determined by the wish to remove or reduce significantly excessive moistening that accompanies the drying technology in induration machines with reverse of the heat medium. The high efficiency of the drying process by downdraft (from top downward) has made to focus toward the technology of non-reverse pellet drying by means of the two-layer drying method providing successive drying of each layer. This method solves the problem of an increased height of the initial pellet layer with the minimum overmoisturizing in the process of drying $[15,16]$. The total layer height reaches a higher value than at one-layer charging with significantly lower overmoisturizing of the pellets. The height of each layer can be up to $250 \mathrm{~mm}$. The total height of the pellet layer will be $500 \mathrm{~mm}$, which enables to increase significantly the productivity of the induration machine. Apart from the productivity growth, the advantages of this solution are as follows:

1. minimum overmoisturizing of the layer;

2. significantly higher intensity of the drying process;

3. improved quality of the fired pellets; and

4. reduced fuel consumption by $25-30 \%$. 
TABLE 2: Main process parameters during processing of different ores and production of various-purpose pellets.

Process stage
Ore type

Oxidized BIF

Ore disintegration and classification; with production of products ground to the given size:

- specific surface, $\mathrm{cm}^{2} / \mathrm{g}$

1500

1850

Magnetic and floatation concentration with production of iron-ore concentrate slurry containing, \% $-\mathrm{Fe}$

$-\mathrm{SiO}_{2}$

2.75

Thickening and dewatering of concentrate slurry

up to humidity, $\%$

9.95

9.7

Preparation of burden consisting of

non-oxidized BIF concentrate, bentonite, limestone

\begin{tabular}{|c|c|}
\hline lid & d fU \\
\hline
\end{tabular}

bentonite $0.7 \%$

Burden pelletizing with production of green pellets of the following quality:

- moisture content, \%

- crushing strength, kN/pel,

minimum

- ductility, times, minimum

Screen separation of suitable green pellets:

- size, $\mathrm{mm}$

- content, $\%$

Charging of green pellets in the induration machine and heat treatment at MOK-1-592 for pelletizing:

- type

- productivity, t/h

- specific fuel consumption, $\mathrm{m}^{3} / \mathrm{t}$

$\mathrm{Fe}$

$-\mathrm{FeO}$

\begin{tabular}{|c|c|}
\hline non-fluxed & fluxed \\
\hline 631 & 572 \\
\hline$<10$ & $<12.5$ \\
\hline 63.2 & 60.5 \\
\hline$<1.0$ & $<1.5$ \\
\hline
\end{tabular}

9.8

1.6

1.8

3.5
3.5

$10-16$

$95 \%$
10-16

$95 \%$
$10-12.5$

$80 \%$ for blast-furnace for metallization production

631

$<10$

64.8

$<1.2$
570

$<11.5$

66.0

$<0.5$

As the velocities of filtration in the first drying zone (hereinafter referred to as C1) and the second zone after additional charging (hereinafter referred to as $(-2)$ are 
significantly different, the heights of these 'half-layers' shall also be different. To determine the optimum ratio between the 'half-layer' heights, we performed mathematical modelling with the total layer height of $370 \mathrm{~mm}$, the velocity in $(\mathrm{C}-1)$ was taken equal to $1.5 \mathrm{~m} / \mathrm{s}$ and the velocity of filtration in (C-2) decreases over the length from $1.0 \mathrm{~m} / \mathrm{s}$ to $0.7 \mathrm{~m} / \mathrm{s}$. The height of the first (bottom) 'half-layer' was varied in the range from 130 to $230 \mathrm{~mm}$. The temperature of the heat medium at the entry to $(\mathrm{C}-1)$ was taken $350^{\circ} \mathrm{C}$ and at the entry to $(\mathrm{C}-2)-360^{\circ} \mathrm{C}$. The length of $(\mathrm{C}-1)$ was chosen in such a way that the drying degree of the bottom 'half-layer' before (C-2) was ensured within 80-100\%.

The calculation results are given in Figure 2 . The analysis of these results has shown that the layer height in $(\mathrm{C}-1)$ shall be taken $\geq 210 \mathrm{~mm}$, that is, the height of the second 'half-layer' will be $\leq 160 \mathrm{~mm}$ (Figure 2(a)). The level the drying end is always virtually at the boundary between the 'half-layers', that is, at the bottom of the top 'half-layer' that sets limits to the end of the drying process (Figure 2(b)). (The drying process is deemed to be completed when $80 \%$ of moisture is removed.)

The increased quantity of free moisture at the growth of the first (bottom) layer height (Figure 2(a)) can be explained by a lower gas temperature at the layer exit, which is accompanied by a higher intensity of water vapor condensation at lower levels. In addition, after charging of the top layer we observed more intensive condensation of water vapor at cold lower levels of the first layer.

The further analysis has shown that for maintenance of the required drying parameters and induration machine operation parameters the layer heights can be taken $255 / 145$. In this case, the total height of the layer considering the bed of $70 \mathrm{~mm}$ will be $470 \mathrm{~mm}$. However, implementation of this measure will require higher sides of pallet cars and uplifting of induration machine hearths.

The thermal system of the modernized machine of $430 \mathrm{~m} 2$ area is shown in Figure 3. The operating parameters of the machines before and after the reconstruction are given in Table 1.

The experience in thermal system modernization for hematite pellet production enabled to develop a pelletizing technology using oxidized banded iron formations at MOK-1-592M. Specific features of production of different concentrates and pellets were taken into account for development of the integrated technology, which determined its flexibility and application for production of high-quality pellets from different ores. The technology makes it possible to get high-quality pellets with a low content of silicon and high content of iron using concentrates of oxidized banded iron formations [17] for blast-furnace production and metallization (Table 2). 
At present, the elements of the new thermal system already proved are used for modernization of OK-306 at Lebedinsky GOK [18]. Moreover, they consider a possibility to use the elements of this design for OK-536 at Karelsky Okatysh Mining Plant and OK-520 at Mikhailovsky GOK.

\section{Conclusions}

1. The improved mathematical model based on the solution of kinetic and heat-andmass exchange equations with regard to mineralogical, physical and chemical properties of the initial raw material as well as requirements for finished product quality makes it possible to optimize the design of the new thermal system, process operating parameters and conditions for pellet heat treatment.

2. An energy-efficient thermal system of the conveyor-type induration machine of new generation has been developed.

3. The main solutions used in the energy-efficient thermal system distinguishing it from Russian and foreign counterparts are as follows:

(a) the overflow system of collectors, including a central collector and two lateral collectors, provides the maximum utilization of sensible heat of fired pellets at cooling with selective distribution in a fanless way and

(b) the gas flue system provides recirculation of the heat medium with a high degree of waste heat utilization and minimum quantity of emissions into the atmosphere.

4. The main technological and structural solutions used in the new thermal system can be applied for improvement of existing technologies and designing of new pelletizing plants.

\section{References}

[1] Kurunov, I. F. (2017). The condition and tendencies of ferrous metallurgy development in the world in the light of the 21st century's challenges. Iron Making Challenges of the 21st Century, in Proceedings of the 8th International Congress of Blast-Furnace Operators, pp. 10-20. M.: Kodeks Publishing House.

[2] Geerdes, M., Chaigneau, I., Kurunov, O., et al. (2016). Modern Blast Furnace Ironmaking. Introduction, p. 280. M.: Metallurgy. 
[3] Tretyak, A. A. (2017). Blast furnace production in Russia in 2011-2016 in the light of the 21st century's challenges. Iron Making - Challenges of the $21^{\text {st }}$ Century, in Proceedings of the 8th International Congress of Blast-Furnace Operators, pp. 21-34. M.: Kodeks Publishing House.

[4] Stoilensky, G. O. K. (November-December 2016). No Margin for Error. Metal Courier, p.16-20.

[5] Lavrinenko, A. A., Varichev, A. V., Ugarov, A. A., et al. (2017). Innovative heating system in the MOK-1-592 roasting machine. Steel in Translation, vol. 47, no. 12, pp. 806-813.

[6] Anisimov, N. K., Naftal, M. N., Maslov, E. V., et al. (2016). Modernization of production at Ural Steel as a part of METALLOINVEST's development strategy. Metallurg, no.7, pp. 4-6.

[7] Abzalov, V. M., Evstyugin, S. N., Bragin, V. V., et al. (2008). Leleko development of a new-generation conveyer roasting machine. Steel in Translation, vol. 38, no. 12, pp. 999-1000.

[8] Abzalov, V. M., Bragin, V. V., Nevolin, V. N., et al. (2010). Modernization of roasting machines within the commonwealth of independent states. Steel in Translation, vol. 40, no. 9, pp. 810-812.

[9] Abzalov, V. M., Bragin, V. V., Klein, V. I., et al. (2010). Thermal systems of conveyer roasting machines. Steel in Translation, vol. 40, no. 9, pp. 813-815.

[10] Bokovikov, B. A. , Bragin, V. V. , Shvydkii, V. S. (2014). Role of the thermal-inertia zone in conveyer roasting machines. Steel in Translation, vol. 44, no. 8, pp. 595-601.

[11] Bokovikov, B. A., Bragin, V. V., Malkin, V. M., et al. (2010). Solodukhin mathematical model of the conveyor induration machine as a tool for optimization of its thermal system. Steel, no.9, pp. 33-37

[12] Evstzugin, S. N., Bragin, V. V., Solodukhin, A. A., et al. (28 April 2018). Pelletizing Method and Arrangement, Patent No. 2652584

[13] Kretov, S. I., Kozub, A. V., Pigarev, S. P., et al. (2017). Induration machine of new generation as a tool of client-oriented pellet production. Steel, no.12.

[14] Lavrinenko, A. A., Varichev, A. V., Ugarov, A. A., et al. (2017). Thermophysical regularities underneath the innovative heat engineering system of the induration machine MOK-1-592. Steel, no.12.

[15] Bokovikov, B. A., Soloduchin, A. A., and Spirin, N. A. (2014). Reduction of pellet overmoisturizing in the drying zone of induration conveyor machine, Steel, no. 8, pp. 14-17. 
[16] Bokovikov, B. A., Klein, V. I., Malkin, V. M. et al. (2003). Mechanism of pellet overmoisturizing area formation in the drying zone of the induration conveyor machine. Steel, no.9, pp. 20-24.

[17] Bersenev, I. S., Bormotova, I. G., Vokhmyakova, I. S., et al. (2017). Yaroshenko Utilization of iron-bearing wastes of magnetic concentration - oxidized banded iron formations of the Kursk Magnetic Anomaly, in Proceedings of the Congress with International Participation and Conference of Young Scientists 'Fundamental research and applied developments in the field of processing and utilization of man-made mineral formations (TECHNOGEN-2017)', V Forum 'Ural market of scraped metal, industrial and household wastes', Pp. 193-196. Ekaterinburg: UrO RAN.

[18] Ugarov, A. A., Martinson, V. N., Evstyugin, S. N., et al. (2017). Improvement of ironore pellet production at a plant. Mining Journal, no. 5 . 